\title{
Remote Robot Execution through WWW Simulation
}

\author{
S.T. Puente, F. Torres, F. Ortiz, F.A. Candelas \\ Automatics and Computer Vision Group (http://www.disc.ua.es/gava) \\ Dept. of Physics, Systems Engineering and Signal Theory. \\ University of Alicante (Spain) \\ spuente@disc.ua.es
}

\begin{abstract}
Nowadays, every industry's goal is to improve their manufacturing processes and to increase their cadence of production, in order to be competitive. This goal usually implies a higher automation level (i.e. an increase on the number of robots used in the production chain) and also a more efficient use of the existing robots.

This paper shows the state of art on teleoperation and simulation systems and proposes some possible network architectures devoted to the development of such systems. $A$ method for the optimization of robot tasks is also suggested. The application proposed can teleoperate a robot arm with five degrees of freedom through Internet by using a previous simulation system and visual feedback. This simulation can be accessed simultaneously by different workers. As a result, the number of robots required can be reduced on new applications or dangerous environments.
\end{abstract}

\section{Introduction}

Nowadays several virtual systems exist in Internet that allow to manage or to learn disciplines like robotics, artificial vision, etc [1][2][3]. Most of these systems permit the use of physical system without a previous simulation, what makes the workers to be proceeded sequentially, lacking of an important factor at time of being used for a group.

This publication presents a system for the use of a robot arm that permits its concurrent utilization without causing problems to the system.

In the next point a state of art in simulation and teleoperation systems are presented. The possible system architectures are shown in the thirtd point. The proposed system is described in the fourth section. The conclusions are exposed in the fifth point.

\section{State of art}

There are many ways to achieve environments that emulate the reality. The most traditional method is to reproduce physically, at different or equal scale, the original system; other way is through the use of a visual feedback, the original system is recorded [4][5][6] and this feedback reproduces the system for us. Currently the most interesting way of doing it is through virtual environments, generated by computer simulations. [7] [8]

Virtual environments are used to get real system simulations, reducing costs on test measurements as well as providing a better a way to learn for the worker.

These environments also permit the immersion of the worker in the simulation, through stereoscopic glasses.

The use of robots in dangerous places for people, radioactive materials handling, explosives detonation, as well as to carry out various types of tasks in the space, submarine exploration, microassembly, mining,... [9] are different advantages of robots versus humans. Initially the telemanipulator is used for these tasks; it permits to carry out the orders of the worker by a set of simple controls without the physical necessity of having a direct control.

In the master/slave systems, a robot arm (master) of equal form, although it can have different size, is manipulated by the worker by reproducing the movements of this in the remote robot (slave). $[10][11][12]$

A new system could be gotten by mixing simulated environments and teleoperated systems where the user has a real simulation system which is reproduced by the real one. [3]

This last type of systems could offer in addition to simulation a feedback to the worker through images. [3][7]

Remark that in teleoperated systems through virtual environments this could be remote control. The physical presence of the worker near the system is not necessary as telemanipulators or traditional master/slave systems. System operation could be remote control through Internet by using VRML and Java. The first one allows to simulate virtual systems easily and Java language lets the worker to interact with the environment and the real system at same time. [8][13][14][15][16][17] 


\section{General architecture}

Teleoperation systems using simulation permits diverse architectures in their design.

The first option consists of carrying out the simulation and the teleoperation, on the same computer, the worker computer, so the computer where is executed the simulation is the same that is connected to the robot controller in order to send orders to it. In this system the worker must be close to the controller; the maximum distance to connect the computer to the controller, usually by a serial port, what implies a maximum distance of $15 \mathrm{~m}$ according to the RS232 norm.

Another way consists of setting the simulation and teleoperation systems separated. The simulation takes part into the worker computer. This system permits the worker be further than the previous one because it can be interconnected by a local network.

A last possibility could be to have the systems completely separated. The worker works from a computer and in other one the calculus of simulation is made. A third computer is connected with the robot controller in order to send it orders. This system, as the previous one, let the worker works at greater distance thanks to the computers distribution in a local network but also has the advantage of doing a distribution task saving resources due to each computer makes a specific task, optimizing the response time of the system.

\subsection{Internet architecture}

Architectures proposed previously could be implemented in Internet, although one must keep in mind certain restrictions as the limited bandwidth of the connection, the safety using the robot, etc. [17]

The most standardized way of connecting the system to Internet would be through a HTML page. This possibility is restricted due to the limitations of this language, so the architectures based on Java are proposed by creating an applet that allows to manage the system where Java3D, VRML could be use to carry out the simulation. [3][8]

An option to carry out the simulation is to use the web server as the same computer connected to the robot controller, with will operate all the necessary calculations. [1]

Another possibility is to carry out the calculations from a different computer.

For teleoperation the computer that is connected to the robot controller could be connected to the web server through a local network. So the worker could carry out all operations through the web server, and as a result the robot remains protected from a direct access. Also the bandwidth required for this is minimum because one must only transmit the teleoperation orders. [7]

\section{Application purpose}

The description of the application is shown in two parts, a general structure and an operation mode.

The system is based on the last architecture described in 3.1. The teleoperation is separated from the system and the simulation is performed into the worker computer.

The system is operational at http://www.disclab.ua.es/ gava/proyectos/teleoperacion/tele.html

\subsection{General structure}

The architecture of the system is based on a client/server structure through Internet (fig. 1), following the layout of the previous section. VRML has been use for the simulation. [7][8][17]

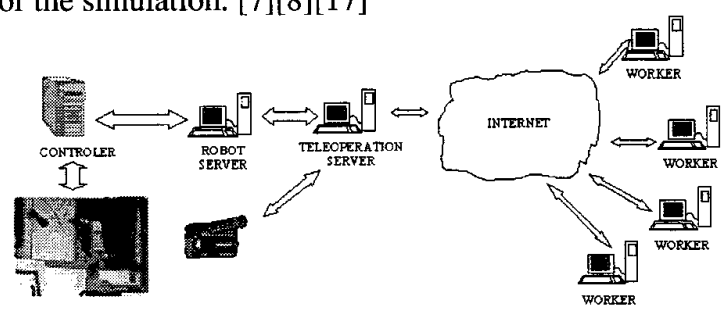

Figure 1. System architecture

The robot that has been applied to the system is the SCORBOT ER-IX of ESHED ROBOTEC with five degrees of freedom.

Its controller is the CONTROLER B of ESHED ROBOTEC, that allows to manage until twelve motors.

The robot controller is communicated by a serial port RS-232 to the robot server.

To the general architecture proposed a camera CDC SONY XC-75CE of $1 / 2$ inch with an objective CANON TV LENS JF7.5mm 1:1.4 has been added. The camera is connected to the web server to transmit a video to the worker applet.

\subsection{Operation mode}

The operation scheme is based on a web page, with an applet in Java [14][15] where one or more workers could be connect to the simulation. This allows the workers to carry out various simulation movements of the robot arm as well as example exercises to learn the basic use of it, all of them through simulation. 

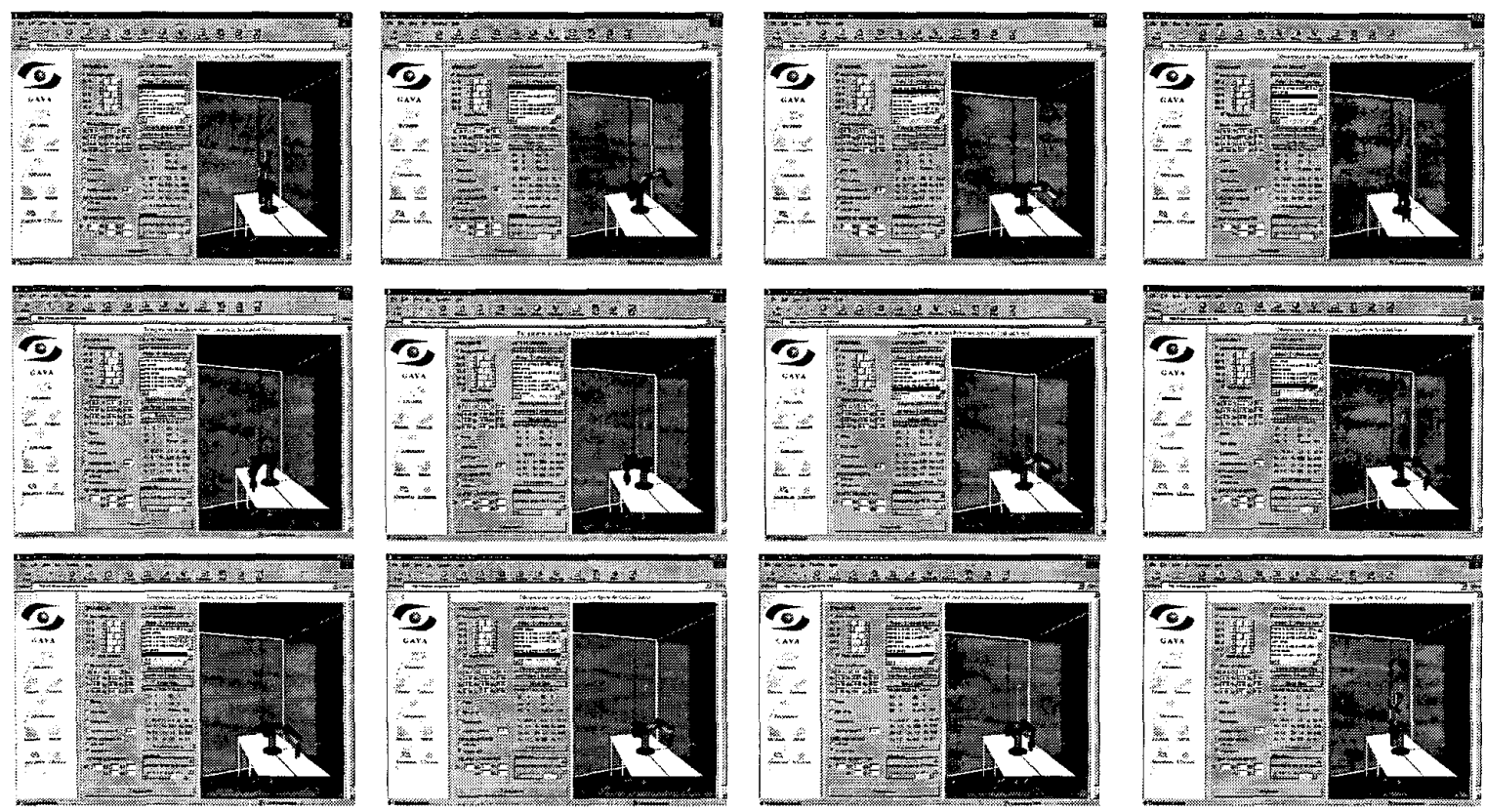

Figure 2. System simulation
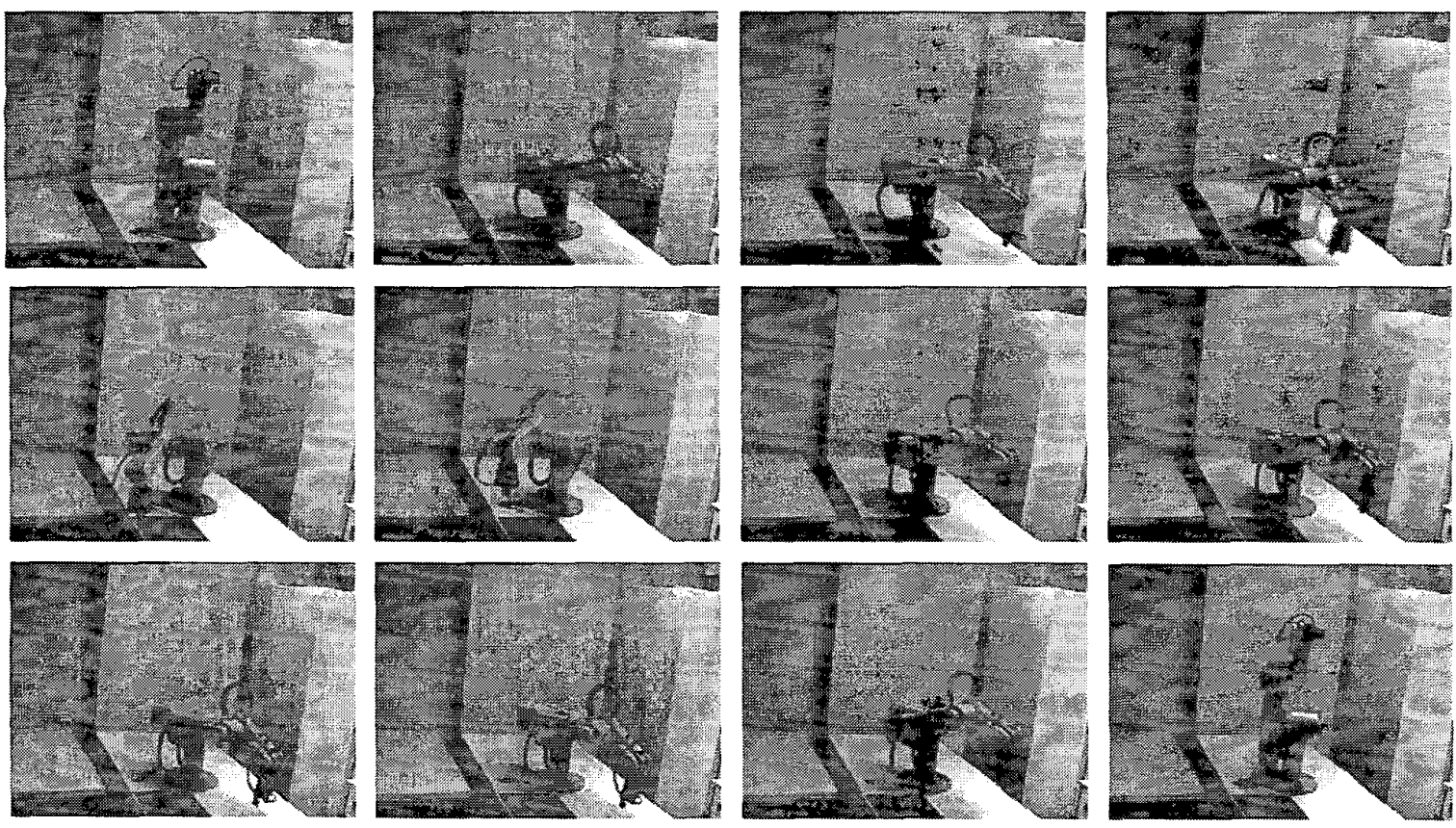

Figure 3. Video of real execution 
This is visualized in VRML [13][14][16], together with applet that gives the worker all the possibilities of simulation and visualization from different perspectives (fig.2).

Due to the system multiples workers design are permitted to simulate concurrently getting the maximum profit of the available resources.

Afterwards, on worker request, the system permits the realization of the simulated movements over the real arm; for this purpose the robot server is designed (fig. 1). The worker must authorized to do it. Parallel the worker could simulate another movements in order to carry out a different task, as it would occur in disassembly systems or in dangerous substance management where the task are or in dangerous substance management where the task are always different.

The requests for using the real system are managed by a FIFO queue.

The server will indicate to the worker the time left to do the request operations on the real arm according to the state of the system.

The execution access is administrated through requests in the teleoperation server. Also the server keeps a full report about all the accesses of each worker and what they have done.

When the worker is allowed to carry out the execution over the robot, the server notifies to the camera that will produce an AVI video of the arm movements, and will transmit it to the applet so that the worker could see the results (fig. 3). [4][5][6]

\section{Conclusions}

This system permits an easy way of learning the basic movements of a robot. This is useful for training workers in managing industrial robots, in the redesign of industrial applications, etc.

Besides carrying out a simulation, it permits the use of a real robot to see the results, what implies a consequent added learning.

On the other hand it has the great advantage of being an Internet system, which permits an easier and bigger diffusion as well as the use of a robot arm for different workers, that involves a greater profit in the expenditure done.

Others advantages of the system are: it shows a distributed philosophy. The simulation could operate independently of the execution of the robot arm. This could be useful, for instance, in non-predetermined tasks.

\section{References}

[1] J.M. Sebastián, D. García, D. Santos, P. Campoy, "Proyecto Titere. Realización de Prácticas de Laboratorio en Puestos de Trabajo Remotos mediante la Transmisión de Imágenes por Red
Telefónica Conmutada" XIX Jornadas de Automática, 1998, pp 21-26.

[2] Ambientes virtuales en Internet: una propuesta orientada a teleoperación. http://www.mox.uniandes.edu.co/proyectos.html

[3] Teleoperation projects and virtual environments http://www.mox.uniandes.edu.co/proyectos/1998/ambientes_virt uales

[4] Heiner Wolf, Konrad Froitzheim, "Inline Video - A new application for Standard Mechanisms", Poster proc. of the Third International World-Wide Web Conference, Darmstadt, April'95

[5] Klaus H. Wolf, Konrad Froitzheim, Michnel Weber, "Interactive Video and Remote Control via the World Wide Web", Lecture Notes in Computer Science 1045, Interactive Distributed Multimedia Systems and Services, Berlin, March 1996

[6] Heiner Wolf, Konrad Frotzheim, "WebVideo a Tool for WWW-based Teleoperation”, Proc. IEEE ISIE'97, Grimaraes, July 7, 1997.

[7] F. Torres, S.T. Puente, I. Damas, C. Puerto, F.A. Candelas. "ASTRO: Aprendizaje mediante Simulación y Teleoperación de Robots". Proc. XX Jornadas de Automática. 1999. pp. 209-213

[8] Holger Bönisch, Stefan Fiedler, Konrad Froitzheim, Peter Schulthess, "A VRML-based Visualization of User-Vicinities in the WWW", Proc. of the ATMSA $6^{\text {th }}$ International Conference on Telecommunications, Nashville, Mar. 1998.

[9] Some background on teleoperation and haptic interfaces. http://www.ee.ebc.ca/home/staff/faculty/tims/etc/www/bg_tel.ht $\mathrm{ml}$

[10] Antonio Burriertos, Luis Felipe Peñín, Carlos Balaguer, Rafael Aracil, Fundamentos de Robótica, Mc Graw Hill. 1997. pp.8-130.

[11] K.S. Fu, R.C. Gonzalez, C.S.G. Lee. Robótica Control, Detección, Visión e Inteligencia. Mc Graw Hill. 1988. pp. 1-84.

[12] J.M. Azorín, R. Saltaren, J.M. Sabater, R. Puerto, "Simulador de un Sistema de control Maestro-esclavo de N GDL", proc. XX Jornadas de Automática. 1999. pp. 505-508

[13] Standard specification of VRML. http://www.vrml.org/fs_ specifications.htm

[14] EAI (External Authoring Interface). API to connect Java and VRML. http://www.web3d.org/WorkingGroups/vrml-eai/.

[15] Java 1.2. API User's Guide. Sun's Microsystems, Inc. http://www.javasoft.com.

[16] Bibliography reference for VRML. http://www.sgi.com.

[17] Holger Bönish, Stefan Fiedler, Konrad Froitzheim, Peter Schulthess, "Visualizing the User Space of the WWW with VRML", Virtual Environments 98, Stutgart, Jun 1998.

[18] Issues in Internet Telerobotics. http://telerobot.mech.uwa. edu.au/ROBOT/anupaper.htm 